\title{
Acute and Sustained Effects of Methylphenidate on Cognition and Presynaptic Dopamine Metabolism: An $\left[{ }^{18}\right.$ F]FDOPA PET Study
}

\author{
Ina Schabram, ${ }^{1}$ Karsten Henkel, ${ }^{1}$ Siamak Mohammadkhani Shali, ${ }^{2}$ Claudia Dietrich, ${ }^{1}$ Jörn Schmaljohann, ${ }^{2}$ \\ Oliver Winz, ${ }^{2}$ Susanne Prinz, ${ }^{8}$ Lena Rademacher, ${ }^{1,10}$ Bernd Neumaier, ${ }^{11}$ Marc Felzen, ${ }^{5}$ Yoshitaka Kumakura, ${ }^{4}$ \\ Paul Cumming, ${ }^{3,9}$ Felix M. Mottaghy, ${ }^{2,6,7}$ Gerhard Gründer, ${ }^{1,6}$ and Ingo Vernaleken ${ }^{1,6}$ \\ ${ }^{1}$ Department of Psychiatry, Psychotherapy and Psychosomatics, RWTH Aachen University, 52074 Aachen, Germany, ${ }^{2}$ Department of Nuclear Medicine, \\ RWTH Aachen University, 52074 Aachen, Germany, ${ }^{3}$ Department of Nuclear Medicine, University of Erlangen/Nürnberg, 91054 Erlangen, Germany, \\ ${ }^{4}$ Department of Nuclear Medicine, Graduate School of Medicine, University of Tokyo, 7-3-1, Hongo, Bunkyo-ku, Tokyo 113-8654 Japan, ${ }^{5}$ Department of \\ Anesthesiology, University Hospital of the RWTH Aachen University, 52074 Aachen, Germany, ${ }^{6}$ Jülich/Aachen Research Alliance, Jülich/Aachen, 52074 \\ Aachen, Germany, ${ }^{7}$ Department of Nuclear Medicine, Maastricht University Medical Center, 6229 HX Maastricht, The Netherlands, ${ }^{8}$ Department of \\ Psychiatry, Psychotherapy and Psychosomatics, University Hospital of Zurich, 8006 Zurich, Switzerland, ${ }^{9}$ Department of Neuroscience and Pharmacology, \\ Copenhagen University, 1165 Copenhagen, Denmark, ${ }^{10}$ Department of Child and Adolescent Psychiatry, University of Marburg, 35039 Marburg, Germany, \\ and ${ }^{11}$ Max-Planck-Institute for Neurological Research, 50931 Cologne, Germany
}

Methylphenidate (MPH) inhibits the reuptake of dopamine and noradrenaline. PET studies with MPH challenge show increased competition at postsynaptic $\mathrm{D}_{2 / 3}$-receptors, thus indirectly revealing presynaptic dopamine release. We used $\left[{ }^{18} \mathrm{~F}\right]$ fluorodopamine $\left(\left[{ }^{18} \mathrm{~F}\right]\right.$ FDOPA)-PET in conjunction with the inlet-outlet model (IOM) of Kumakura et al. (2007) to investigate acute and long-term changes in dopamine synthesis capacity and turnover in nigrostriatal fibers of healthy subjects with MPH challenge. Twenty healthy human females underwent two dynamic $\left[{ }^{18} \mathrm{~F}\right]$ FDOPA PET scans ( $124 \mathrm{~min}$; slow bolus-injection; arterial blood sampling), with one scan in untreated baseline condition and the other after MPH administration $(0.5 \mathrm{mg} / \mathrm{kg}$, p.o.), in randomized order. Subjects underwent cognitive testing at each PET session. Time activity curves were obtained for ventral putamen and caudate and were analyzed according to the IOM to obtain the regional net-uptake of $\left[{ }^{18} \mathrm{~F}\right] \mathrm{FDOPA}\left(K\right.$; dopamine synthesis capacity) as well as the $\left[{ }^{18} \mathrm{~F}\right]$ fluorodopamine washout rate $\left(k_{\text {loss }}\right.$, index of dopamine turnover). MPH substantially decreased $k_{\text {loss }}$ in putamen $(-22 \% ; p=0.003)$. In the reversed treatment order group (MPH/no drug), $K$ was increased by $18 \%$ at no drug follow-up. The magnitude of $K$ at the no drug baseline correlated with cognitive parameters. Furthermore, individual $k_{\text {loss }}$ changes correlated with altered cognitive performance under MPH. $\left[{ }^{18} \mathrm{~F}\right]$ FDOPA PET in combination with the IOM detects an MPH-evoked decrease in striatal dopamine turnover, in accordance with the known acute pharmacodynamics of MPH. Furthermore, the scan-ordering effect on $K$ suggested that a single MPH challenge persistently increased striatal dopamine synthesis capacity. Attenuation of dopamine turnover by MPH is linked to enhanced cognitive performance in healthy females.

Key words: $\left[{ }^{18} \mathrm{~F}\right]$ FDOPA PET; cognition; dopamine turnover; long-term effects; methylphenidate; stimulants

\section{Introduction}

Methylphenidate $(\mathrm{MPH})$ facilitates dopaminergic transmission by inhibiting the dopamine reuptake transporter (DAT). In clin-

\footnotetext{
Received April 16, 2014; revised Sept. 5, 2014; accepted Sept. 11, 2014.

Author contributions: Y.K., P.C., F.M.M., G.G., and I.V. designed research; I.S., K.H., S.M.S., C.D., J.S., O.W., S.P., L.R., B.N., M.F., and I.V. performed research; I.S., J.S., and 0.W. analyzed data; I.S., K.H., S.P., P.C., and I.V. wrote the paper.

This work was supported by the German Research Foundation (DFG, VE 466/2-1 and IRTG 1328, International Research Training Group) and Brain Imaging Facility of the Interdisciplinary Center for Clinical Research (IZKF) at the RWTH Aachen University, Germany. We thank the student assistants for their support.

The authors declare no competing financial interests.

Correspondence should be addressed to Ina Schabram, Department of Psychiatry, Psychotherapy, and Psychosomatics, RWTH Aachen University Pauwelsstrasse 30, D-52074 Aachen, Germany. E-mail: ischabram@ukaachen.de.

DOI:10.1523/JNEUROSCI.1560-14.2014

Copyright $\odot 2014$ the authors $\quad 0270-6474 / 14 / 3414769-08 \$ 15.00 / 0$
}

ical practice, $\mathrm{MPH}$ is treatment of choice in attention deficit/ hyperactivity disorder (ADHD). Because of its straightforward pharmacodynamic mechanism, MPH has also been used as a challenge in PET investigations inducing increased competition between $\mathrm{D}_{2 / 3}$-receptor ligands and endogenous dopamine (Volkow et al., 1994; Rosa-Neto et al., 2005). This MPH-induced reduction of the ligand binding potential, however, is a surrogate parameter of the changes in dopamine concentrations and is confounded by some biological processes, such as receptor internalization (Skinbjerg et al., 2010). The present approach using $\left[{ }^{18} \mathrm{~F}\right]$ fluorodopamine ( $\left.\left[{ }^{18} \mathrm{~F}\right] \mathrm{FDOPA}\right)$ does not target the estimation of dopamine release but mimics the presynaptic synthesis pathway of dopamine. Given that the primary application of $\mathrm{MPH}(\mathrm{ADHD})$ is claimed to be characterized by presynaptic dis- 
turbances (e.g., Ernst et al., 1998; Volkow et al., 2007; Ludolph et al., 2008), the evaluation of MPH effects by a predominantly presynaptic tracer appears to be reasonable.

Until now, $\left[{ }^{18} \mathrm{~F}\right]$ FDOPA PET was not used for the evaluation of MPH effects; it traces the dopamine synthesis capacity in brain, which appears to be less vulnerable for environmental and pharmacological influences (Gründer et al., 2003; Vernaleken et al., 2013). However, most quantitative FDOPA PET studies assume irreversible trapping of $\left[{ }^{18} \mathrm{~F}\right] \mathrm{FDOPA}$, whereas the inlet-outlet model (IOM) of Kumakura et al. (2007) yields the net clearance of $\left[{ }^{18} \mathrm{~F}\right]$ FDOPA to brain $\left(K ; \mathrm{ml} \cdot \mathrm{g}^{-1} \mathrm{~min}^{-1}\right)$, accommodating the delayed washout of decarboxylated and deaminated metabolites, which is explicitly defined by the rate constant $k_{\text {loss }}(\mathrm{min})$. Thus, the $\left[{ }^{18} \mathrm{~F}\right]$ FDOPA IOM can reveal acute changes in the dopamine dynamics.

Using this model, the present investigation intends to monitor the acute and delayed effects of MPH on dopamine turnover $\left(k_{\text {loss }}\right)$ and dopamine synthesis capacity $(K)$ as well as respective correlations with cognitive changes. Because DAT inhibition will reduce the rate of dopamine reuptake into the cytosolic compartment where it would be exposed to monoamine oxidase (Nielsen et al., 1983; Zetterström et al., 1988), we hypothesize that the magnitude of $k_{\text {loss }}$ will be reduced. We furthermore expect that changes in $k_{\text {loss }}$ correlate with enhancement in cognition under MPH treatment.

Therefore, two $\left[{ }^{18} \mathrm{~F}\right] \mathrm{FDOPA}$ PET scans (A: untreated control condition; B: scan after MPH challenge) were conducted in healthy subjects. Because long-term effects of psychostimulants on dopamine transmission and sensitization are known (Calipari et al., 2014), this study was conducted with two treatment order groups (no drug/MPH and MPH/no drug) to obtain possible regulatory effects of a single MPH dose on presynaptic dopamine metabolism.

\section{Materials and Methods}

Subjects. Twenty healthy, nonsmoking female subjects 21-28 years of age (mean \pm SD, $24.0 \pm 1.9$ years) were included in the study, which had been approved by the Research and Ethics Committees of the University Hospital of RWTH Aachen University. All subjects provided written informed consent. Exclusion criteria for the volunteers included current neurological, psychiatric, or systemic disease, pregnancy (13 of 20 subjects were using oral contraceptives), and current use of drugs affecting the CNS. All 20 subjects are a small subgroup of a large neurogenetic study group of women $(n=200)$ not including molecular imaging techniques (Schabram et al., 2013). The cohort is well characterized in respect to demographics, and by intention highly homogeneous in age, gender, and education. Men were not included to reduce heterogeneity and to improve the statistical power for main effects. The 20 PET subjects were randomly distributed into two treatment groups (usual or reversed order of baseline/MPH PET scans). To optimize statistical power for the two main hypotheses, the groups were asymmetrically distributed, with 14 receiving first the unmedicated control scan, followed by the MPH condition, and six being scanned in reversed order.

Neuropsychology. To investigate the prefrontal cognitive capacities of the participants in the two scanning conditions, we administered the Trail Making Test (TMT-A+B) of executive functioning (Reitan, 1955), Stroop test (Bäumler, 1985), d2-concentration test of attention (Brickenkamp, 2002), and degraded stimulus continuous performance task (dsCPT) for measuring attention, in which subjects need to react on either a degraded or contoured target stimulus (Schabram et al., 2013). Following upon Kathmann et al. (1996), dsCPT was analyzed according to the signal detection theory (SDT) (Peterson et al., 1954). The test parameters for hits, missed, false alarms, and correct rejections were entered into analysis using BayesSDT software package for MATLAB (Lee, 2008) to obtain the following primary outcome variables: discriminability (sensitivity index, $\mathrm{d}^{\prime}$ ) and decision-bias $(\beta)$. This bias indicates either a more liberal (negative values) or a more conservative (positive values) trend toward accepting a stimulus as a target and is independent of the overall performance. The first part ( $\mathrm{d} 2$ test and TMT) of neuropsychological testing was performed $\sim 1 \mathrm{~h}$ before PET scan, whereas for technical reasons the dsCPT was performed after scan.

MPH challenge. Participants received MPH (Ritalin, Novartis Pharmaceuticals) at a dose of $0.5 \mathrm{mg} / \mathrm{kg}$ adjusted for body weight either at first $(n=6)$ or second PET scan $(n=14)$. Based upon pharmacokinetics of oral $\mathrm{MPH}$, the drug was administered $2 \mathrm{~h}$ before tracer injection (Markowitz et al., 2003). Because of legal and institutional restrictions, it was not possible to include a placebo drug formulation in the study design. The medication condition was therefore not blinded.

PET scanning and plasma sampling procedure. Before each PET scan, a pregnancy test was performed. $\left[{ }^{18} \mathrm{~F}\right] \mathrm{FDOPA}$ scans were recorded with the Siemens ECAT HR + whole-body PET, which has a field of view of $16.2 \mathrm{~cm}$ in 47 planes, an interplane spacing of $3.375 \mathrm{~mm}$, and an axial resolution of $5.4 \mathrm{~mm}$ FWHM. Decarboxylation of $\left[{ }^{18} \mathrm{~F}\right] \mathrm{FDOPA}$ in peripheral tissues was inhibited by oral administration of carbidopa (Merck Sharp \& Dome, $2 \mathrm{mg} / \mathrm{kg}$ body weight), of which two-thirds were given $1 \mathrm{~h}$ after and one-third before start of the emission recording. After a brief attenuation scan, a dynamic emission sequence lasting 124 min began upon intravenous injection of $\left[{ }^{18} \mathrm{~F}\right] \mathrm{FDOPA}$ at a dose of $226 \pm 21 \mathrm{MBq}$ (range, 166-263 MBq) as a slow bolus. Frame length increased progressively according to the following schedule: $3 \times 20 \mathrm{~s} ; 3 \times 1 \mathrm{~min}, 3 \times 2 \mathrm{~min}$, $3 \times 3 \mathrm{~min}, 15 \times 5 \mathrm{~min}, 3 \times 10 \mathrm{~min}$ interval (Gründer et al., 2003). Blood was automatically drawn from a radial arterial catheter (first $10 \mathrm{~min}$ ), and the radioactivity concentration measured at $1 \mathrm{~s}$ intervals with an online $\gamma$-counter (Allogg ABSS V3) cross-calibrated to the tomograph. Subsequently, a series of 15 arterial blood samples are drawn manually, and their radioactivity concentrations measured using a well counter (PerkinElmer Wizzard2 gamma-counter). The fractions of untransformed $\left[{ }^{18} \mathrm{~F}\right] \mathrm{FDOPA}$ and its major plasma metabolite 3-O-methyl$\left[{ }^{18} \mathrm{~F}\right]$-fluorodopa $\left(\left[{ }^{18} \mathrm{~F}\right] \mathrm{OMFD}\right)$ were measured by reverse-phase high performance liquid chromatography (Cumming et al., 1993) in plasma extracts prepared from arterial blood samples. The continuous plasma fractions of $\left[{ }^{18} \mathrm{~F}\right] \mathrm{FDOPA}$ and OMFD were calculated by interpolation of biexponential functions fitted to the measured fractions, and the two input functions calculated by multiplication with the total blood curve (Gillings et al., 2001).

PET data analysis. Emission images were reconstructed by filtered back projection with a $4 \mathrm{~mm}$ Hanning filter. The dynamic sequence was frame-wise corrected for head motion, using an interframe rigid-body transformation implemented in PMOD (Version 3.4, PMOD Technology). For spatial normalization, the summed images were first coregistered to the individual MR (1.5T MRT Scanner; Philips Gyroscan NT; Philips Medical Systems), and the MR-registered sequence was then normalized to the ICBM-452 template (Mazziotta et al., 2001) using PMOD (Brain Normalization II routine), and a 12 parameter rigid-body transformation. Decay-corrected time activity curves (TACs) were then calculated for a set of volume of interest templates, including cerebellum, and left and right ventral caudate nucleus and ventral putamen. For one participant with contraindications against MR tomography, PET images were registered to a normalized $\left[{ }^{18} \mathrm{~F}\right] \mathrm{FDOPA}$-template.

$\left[{ }^{18} \mathrm{~F}\right]$ FDOPA kinetics. Most brain $\left[{ }^{18} \mathrm{~F}\right]$ FDOPA studies are quantified by linear graphical analysis relative to the arterial $\left[{ }^{18} \mathrm{~F}\right] \mathrm{FDOPA}$ input, or a reference tissue surrogate. With PET recordings of 45-60 min, graphical analysis yields an index of $\left[{ }^{18} \mathrm{~F}\right]$ FDOPA utilization that assumes irreversible trapping, thus ignoring the rapid formation of deaminated $\left[{ }^{18} \mathrm{~F}\right]$ FDOPA metabolites in living striatum, and their diffusion from brain (Cumming et al., 1993). Because this metabolic process entails useful information about the turnover of the neurotransmitter pool, we elected to use the reversible IOM (Kumakura et al., 2007) for kinetic analysis of the regional TACs. The IOM is based on principles similar to those of the reversible tracer model of Sossi et al. (2001), as also used by Cumming et al. (2001); both approaches yield outcome parameters for the net blood-brain clearance of $\left[{ }^{18} \mathrm{~F}\right] \mathrm{FDOPA}$, a fractional rate constant for the diffusion from brain of deaminated $\left[{ }^{18} \mathrm{~F}\right] \mathrm{FDOPA}$ metabolites, and also a distribution volume, which reflects dopamine storage capacity. The approach of Sossi et al. (2001) necessarily entails PET acquisition times of $4 \mathrm{~h}$, whereas the presents IOM applies for recordings of only $2 \mathrm{~h}$ 
Table 1. Cognitive performance scores

\begin{tabular}{|c|c|c|c|c|c|c|c|c|}
\hline & No drug & $N$ & MPH condition & $N$ & Change $(\Delta)$ & $\%$ Change & $Z$ & $p$ \\
\hline IQ & $110.4 \pm 12.1$ & 14 & & & & & & \\
\hline TMT-A (s) & $17.5 \pm 4.5$ & 19 & $16.4 \pm 3.5$ & 20 & -1.17 & -6.67 & -1.187 & 0.235 \\
\hline TMT-B (s) & $34.1 \pm 9.2$ & 19 & $33.5 \pm 9.8$ & 20 & -0.62 & -1.82 & -0.523 & 0.601 \\
\hline Stroop interference & $30.0 \pm 8.1$ & 20 & $29.2 \pm 8.1$ & 20 & -0.74 & -2.47 & -0.709 & 0.478 \\
\hline Decision bias $\beta$ & $0.64 \pm 0.90$ & 19 & $0.34 \pm 0.088$ & 20 & -0.3 & -53.13 & -1.933 & 0.053 \\
\hline Sensitivity d' & $2.00 \pm 0.90$ & 19 & $2.23 \pm 0.93$ & 20 & 0.23 & 11.50 & -1.023 & 0.306 \\
\hline dsCPT hits & $6.74 \pm 2.02$ & 19 & $7.20 \pm 1.79$ & 20 & 0.46 & 6.82 & -0.742 & 0.458 \\
\hline $\mathrm{d} 2$ concentration performance & $246.0 \pm 30.9$ & 19 & $260.8 \pm 28.1$ & 20 & 14.8 & 6.02 & -2.865 & $0.004^{*}$ \\
\hline
\end{tabular}

${ }^{*} p<0.05$.

Table 2. Effect of MPH challenge on $\left[{ }^{18} \mathrm{~F}\right] \mathrm{FDOPA}$ PET kinetic parameters

\begin{tabular}{|c|c|c|c|c|c|c|c|c|c|}
\hline & CTR, no & tion & & $\mathrm{MPH}, \mathrm{m}$ & e conditi & & \%Chanqe. & & \\
\hline & Mean & SD & $N$ & Mean & SD & $N$ & MPH-CTR & Z & $p$ \\
\hline$k_{\text {loss }}$ & & & & & & & & & \\
\hline CN right & 0.0036 & 0.0015 & 19 & 0.0028 & 0.0009 & 20 & $-22 \%$ & -1.972 & $0.048^{*}$ \\
\hline CN left & 0.0035 & 0.0015 & 20 & 0.0031 & 0.0011 & 20 & $-10 \%$ & -1.157 & 0.247 \\
\hline CN bilateral & 0.0036 & 0.0014 & 19 & 0.0030 & 0.0009 & 20 & $-17 \%$ & -1.932 & 0.053 \\
\hline PUT right & 0.0037 & 0.0011 & 19 & 0.0031 & 0.0011 & 20 & $-15 \%$ & -2.093 & $0.036^{*}$ \\
\hline PUT left & 0.0037 & 0.0014 & 20 & 0.0029 & 0.0008 & 20 & $-22 \%$ & -2.949 & $0.003^{* *}$ \\
\hline PUT bilateral & 0.0038 & 0.0012 & 19 & 0.0030 & 0.0008 & 20 & $-20 \%$ & -2.656 & $0.007^{* *}$ \\
\hline$K$ & & & & & & & & & \\
\hline CN right & 0.0198 & 0.004 & 19 & 0.0196 & 0.003 & 20 & $-1 \%$ & -0.322 & 0.748 \\
\hline CN left & 0.0201 & 0.005 & 20 & 0.0198 & 0.003 & 20 & $-1 \%$ & -0.299 & 0.765 \\
\hline CN bilateral & 0.0200 & 0.005 & 19 & 0.0197 & 0.003 & 20 & $-2 \%$ & -0.040 & 0.968 \\
\hline PUT right & 0.0226 & 0.005 & 19 & 0.0224 & 0.004 & 20 & $-1 \%$ & -0.080 & 0.936 \\
\hline PUT left & 0.0224 & 0.005 & 20 & 0.0216 & 0.003 & 20 & $-4 \%$ & -0.672 & 0.502 \\
\hline PUT bilateral & 0.0226 & 0.005 & 19 & 0.0220 & 0.003 & 20 & $-3 \%$ & -0.161 & 0.872 \\
\hline$V_{d}$ & & & & & & & & & \\
\hline CN right & 7.05 & 3.37 & 19 & 7.73 & 2.36 & 20 & $10 \%$ & -1.288 & 0.198 \\
\hline CN left & 7.41 & 3.25 & 20 & 7.41 & 3.25 & 20 & $0 \%$ & -0.560 & 0.575 \\
\hline CN bilateral & 6.96 & 3.28 & 19 & 7.57 & 2.74 & 20 & $9 \%$ & -1.046 & 0.295 \\
\hline PUT right & 6.94 & 2.78 & 19 & 8.19 & 2.85 & 20 & $18 \%$ & -1.569 & 0.117 \\
\hline PUT left & 7.42 & 3.94 & 20 & 8.30 & 2.82 & 20 & $12 \%$ & -1.680 & 0.093 \\
\hline PUT bilateral & 7.14 & 3.23 & 19 & 8.24 & 2.60 & 20 & $16 \%$ & -2.012 & $0.044^{*}$ \\
\hline
\end{tabular}

CTR, No drug condition; CN, caudate nucleus; PUT, putamen; MPH, methylphenidate condition.

${ }^{*} p<0.05$; ** $p 0.01$.

because of a more accurate subtraction of brain radioactivity arising from the peripheral metabolite OMFD. The IOM entails a three-step approach in which a constrained one tissue compartment model is first used to calculate the TAC for plasma-derived $\left[{ }^{18} \mathrm{~F}\right] \mathrm{OMFD}$ in cerebellum, which contains negligible DOPA-decarboxylase activity. Here the permeability ratio $(\mathrm{q})$ for the two substances arising from blood (OMFD/FDOPA) is a fixed parameter (Gjedde et al., 1991; Huang et al., 1991), set to a magnitude of 1.5 , which is the mean of the limited number of explicit measurements (Cumming and Gjedde, 1998). Assuming, like all $\left[{ }^{18} \mathrm{~F}\right] \mathrm{FDOPA}$ models, homogeneous distribution of $\left[{ }^{18} \mathrm{~F}\right] \mathrm{OMFD}$ throughout brain, the curve calculated in cerebellum is then subtracted from the entire 4D PET recording, to isolate the brain contents of $\left[{ }^{18} \mathrm{~F}\right] \mathrm{FDOPA},\left[{ }^{18} \mathrm{~F}\right] \mathrm{FDOPA}$, and its deaminated metabolites, which freely diffuse from brain. The first $20 \mathrm{~min}$ are excluded from the IOM analysis because of the need for an equilibrium for $\left[{ }^{18} \mathrm{~F}\right] \mathrm{FDOPA}$ in brain (Kumakura et al., 2007). Finally, the multilinear form of the IOM is applied to the "cleaned" brain TACs to calculate the steady-state parameters alluded to above: (1) the net bloodbrain clearance of $\left[{ }^{18} \mathrm{~F}\right]$ FDOPA $\left(K, \mathrm{ml} \mathrm{hg}^{-1} \mathrm{~min}^{-1}\right)$, which is an index of dopamine synthesis capacity; (2) the washout rate for $\left[{ }^{18} \mathrm{~F}\right] \mathrm{FDOPA}$ together with its deaminated metabolites $\left(k_{\text {loss }} ; \mathrm{min}^{-1}\right)$, which is comparable with the biochemical assays of dopamine turnover; and (3) the steady-state distribution volume of $\left[{ }^{18} \mathrm{~F}\right] \mathrm{FDOPA}$ together with its decarboxylated metabolites $\left(V_{d} ; \mathrm{ml} / \mathrm{g}\right)$, which is an index of dopamine storage capacity comparable with the effective distribution volume (EDV; $\mathrm{ml} \cdot \mathrm{g}^{-1}$ ) defined by Sossi et al. (2001).

Statistical analyses. Wilcoxon's rank order tests for paired samples were conducted to investigate effects of MPH on cognition and PET parameters $\left(K, k_{\text {loss }}\right.$, and $\left.V_{d}\right)$. The baseline versus MPH condition differ- ences (percentage of the change) were calculated as ([no drug - MPH]/no drug $\times 100) . \Delta$ parameters were calculated for $K, k_{\text {loss }}$, and the cognitive measures (MPH condition subtracted by drug-free condition) indicating the percentage of change. To examine the order of treatment effect, an independent $t$ test was conducted for $\Delta-K$ and $\Delta-k_{\text {loss. }}$. To justify a deeper investigation for treatment order effect, a prescreening threshold of $p<$ 0.2 was applied for the decision to include parameters in the repeatedmeasures ANOVA (i.e., K and treatment order). Furthermore, Spearman correlations between baseline PET parameters and baseline neuropsychology scores, $\Delta$ neuropsychology scores, $\Delta-K$ and $\Delta-k_{\text {loss }}$ were calculated. To correct for multiple testing, a Bonferroni correction at $\alpha=0.05$, calculated by the Dubey/Armitage-Pamar $\alpha$ boundary (Sankoh et al., 1997) was used. This correction includes the correlation among the regions.

\section{Results}

All 20 subjects successfully completed the two PET scans. In two subjects, neuropsychological testing ( $\mathrm{d} 2$ test, TMT-A+B) was lost because of technical problems. Mean IQ was $110.43 \pm 12.13$ (SD) (Table 1). The mean (SD) specific activity of fluorine-18 was $9.4 \pm 1.9 \mathrm{MBq} / \mu \mathrm{mol}$ (range $5.7-13.6 \mathrm{MBq} / \mu \mathrm{mol}$ ), indicating a total injected mass of $\sim 4$ pmol; there were no significant differences in specific activity between the two PET scans $(\mathrm{T}=1.327, p=0.231)$. The mean (SD) dose of MPH was $33.0 \pm 6.4 \mathrm{mg}$ (range $20-50 \mathrm{mg}$ ). There was no group differences in the stage of menstrual cycle at the scanning day, nor any main effect of cycle or oral contraceptive use on any $\left[{ }^{18} \mathrm{~F}\right]$ FDOPA PET parameter at baseline. 

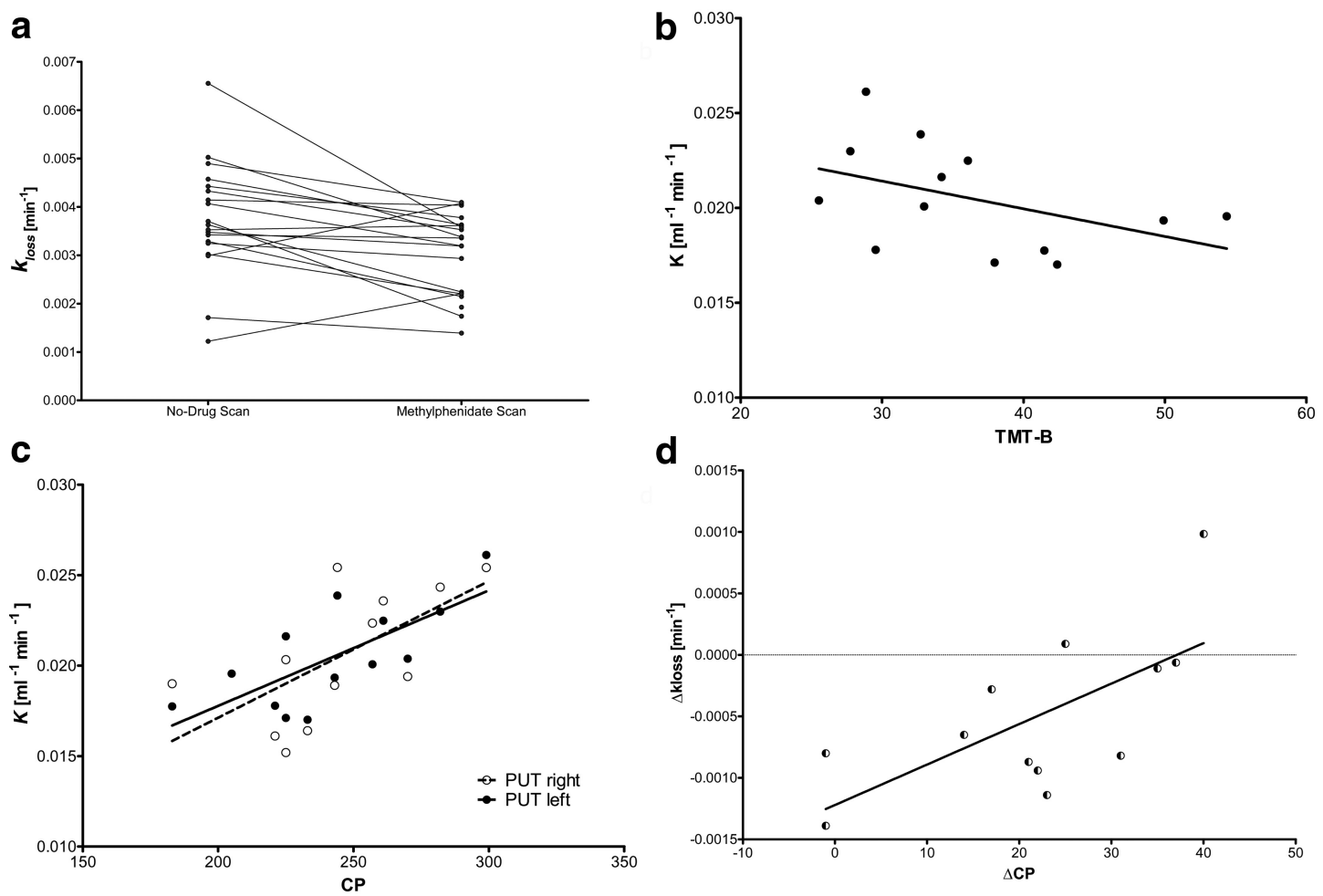

Figure 1. $\quad \boldsymbol{a}$, Reductions in $\left[{ }^{18} \mathrm{~F}\right] \mathrm{FDOPA} k_{\text {loss }}$ in bilateral putamen after MPH challenge ( $p=0.007, n=19$, complete sample). $\boldsymbol{b}$, Correlation between time at Trail Making Test B and no drug $\left[{ }^{18} \mathrm{~F}\right]$ FDOPA K in left putamen $\left(p=0.029, n=14\right.$, conventional order group). $c$, Correlation between no drug $\left[{ }^{18} \mathrm{~F}\right] \mathrm{FDOPA}$ Kand concentration performance parameter $(\mathrm{CP})$ in right and left putamen (PUT) (right: $p=0.039, n=12$; left $p=0.007, n=13$, conventional order group). $\boldsymbol{d}$, Correlation between change in $\left[{ }^{18} \mathrm{~F}\right] \mathrm{FDOPA} k_{\text {loss }}$ and change in concentration performance under MPH ( $p=$ $0.040, n=12$, conventional order group).

\section{Neuropsychological measurements}

The results of the neuropsychological tests are displayed in Table 1. $\mathrm{MPH}$ increased concentration performance parameter $(\mathrm{CP})$ in the $\mathrm{d} 2$ task (control condition: $245.95 \pm 30.86, \mathrm{MPH}: 260.75 \pm$ 28.06 (mean $\pm \mathrm{SD}$ ); $-6.0 \%, Z=-2.87, p=0.004$ ). However, there was no effect of MPH on TMT or dsCPT parameters.

\section{PET parameters baseline}

The mean (SD) magnitudes of $\left[{ }^{18} \mathrm{~F}\right] \mathrm{FDOPA}$ IOM parameters $k_{\text {loss }}, K$, and $V_{d}$ in ventral caudate nucleus and in ventral putamen are reported in Table 2 . The baseline $k_{\text {loss }}$ was $0.0036 \pm 0.0014$ $\min ^{-1}$ in the bilateral caudate nucleus and $0.0038 \pm 0.0012$ $\min ^{-1}$ in the bilateral putamen. There were no significant side differences. Baseline $K$ was $0.0200 \pm 0.005 \mathrm{ml} \cdot \mathrm{g}^{-1} \cdot \mathrm{min}^{-1}$ in the bilateral caudate nucleus and $0.0226 \pm 0.005$ $\mathrm{ml} \cdot \mathrm{g}^{-1} \cdot \min ^{-1}$ in the bilateral putamen. Mean (SD) baseline $V_{d}$ was $6.96 \pm 3.28 \mathrm{ml} \cdot \mathrm{g}^{-1}$ in the bilateral caudate nucleus and $7.14 \pm 3.23 \mathrm{ml} \cdot \mathrm{g}^{-1}$ in the bilateral putamen. In one participant, two ROIs (caudate right and putamen right) were excluded from consideration because of poor fitting outcome.

\section{Effect of MPH on PET parameters}

In the MPH challenge condition, mean $( \pm \mathrm{SD}) k_{\text {loss }}$ was $0.003 \pm$ $0.0009 \mathrm{~min}^{-1}$ in bilateral caudate nucleus and $0.003 \pm 0.0008$ $\min ^{-1}$ in bilateral putamen. Thus, MPH reduced $k_{\text {loss }}$ by $22 \%$ in right caudate nucleus $(Z=-1.97, p=0.048, n=19), 22 \%(Z=$ $-2.95, p=0.003, n=20)$ in left putamen, and $15 \%(Z=-2.09$, $p=0.036, n=19$ ) in right putamen (Table 2; Fig. $1 a)$. Mean (SD) $K$ was $0.0197 \pm 0.003 \mathrm{ml} \cdot \mathrm{g}^{-1} \cdot \mathrm{min}^{-1}$ for bilateral caudate nucleus and $0.0220 \pm 0.003 \mathrm{ml} \cdot \mathrm{g}^{-1} \cdot \mathrm{min}^{-1}$ for bilateral putamen; there were no significant effects of MPH on $K(n=20)$.
Table 3. ANOVA for $\left[{ }^{18} \mathrm{~F}\right] \mathrm{FDOPA} K$ in PUT and CN

\begin{tabular}{llll}
\hline & df & F & $p$ \\
\hline CN & & & \\
$\quad\left[{ }^{18}\right.$ F $]$ FDOPA $K$ & 1 & 0.45 & 0.511 \\
$\quad$ Treatment order & 1 & 3.098 & 0.095 \\
$\quad K \times$ TO & 1 & 4.325 & 0.052 \\
PUT & & & \\
$\quad\left[{ }^{18}\right.$ F $]$ FDOPA $K$ & 1 & 2.291 & 0.147 \\
Treatment order & 1 & 6.042 & $0.024^{*}$ \\
$K \times$ TO & 1 & 8.122 & $0.011^{*}$ \\
\hline
\end{tabular}

PUT, Putamen; $\mathrm{CN}$, caudate nucleus; T0, treatment order.

${ }^{*} p<0.05$.

\section{Order of treatment effect}

To test whether the order of the drug treatment had an effect on the PET parameters, we first performed an independent-sample $t$ test; this showed that $\Delta K$ in bilateral caudate nucleus and bilateral putamen differed between groups (caudate: $\mathrm{T}=1.90, p=0.075$ $n=19$; putamen: $t=2.90, p=0.010, n=19)$. The $\Delta-k_{\text {loss }}$ parameter showed no general effect of treatment order, except in left putamen $(\mathrm{T}=2.589, p=0.019, n=20)$. Because of these results, we performed repeated-measures ANOVAs, including $K$ as a within-subjects variable and "order of treatment" as a betweensubject variable. The tests revealed no main effect of $K$ but a main effect of order of treatment and an interaction effect in bilateral putamen $\left(F=8.426, p=0.01^{\star} ; K^{\star}\right.$ order of treatment; see also Table 3). Bilateral caudate nucleus showed a trend in order of treatment effect. The post hoc analyses revealed that, in those subjects with reversed order of drug application (MPH scan first), baseline K estimates in bilateral putamen were $24 \%$ higher than for the conventional order group $(Z=-2.368, p=0.018, n=19)$, with a trend in 
Table 4. Treatment order effect: post hoc analyses within group differences in bilateral $\left[{ }^{18} \mathrm{~F}\right] \mathrm{FDOPA} K$

\begin{tabular}{|c|c|c|c|c|c|c|c|c|c|c|c|}
\hline Group & {$\left[{ }^{18} \mathrm{~F}\right] \mathrm{FDOPAK}$} & No drug & SD & $N$ & MPH & SD & $N$ & Change $(\Delta)$ & $\%$ Change & $Z$ & $p$ \\
\hline \multirow[t]{2}{*}{ CTR-MPH } & $\mathrm{CN}$ & 0.0204 & 0.0031 & 14 & 0.0218 & 0.0038 & 14 & 0.0014 & $7 \%$ & -1.083 & 0.279 \\
\hline & PUT & 0.0186 & 0.0035 & 14 & 0.0195 & 0.0035 & 14 & 0.0009 & $5 \%$ & -1.642 & 0.101 \\
\hline \multirow[t]{2}{*}{ MPH-CTR } & $\mathrm{CN}$ & 0.0273 & 0.0063 & 6 & 0.0224 & 0.0030 & 6 & -0.0049 & $-18 \%$ & -1.782 & 0.075 \\
\hline & PUT & 0.0230 & 0.0056 & 6 & 0.0200 & 0.0018 & 6 & -0.0030 & $-13 \%$ & -1.992 & $0.046^{*}$ \\
\hline
\end{tabular}

CTR, No drug condition; CN, caudate nucleus; PUT, putamen; MPH, methylphenidate condition.

${ }^{*} p<0.05$.

Table 5. Correlations between neuropsychological parameters and $\left[{ }^{18} \mathrm{~F}\right] \mathrm{FDOPA} K$ in bilateral CN and PUT

\begin{tabular}{|c|c|c|c|c|c|c|c|c|c|c|c|c|}
\hline & \multicolumn{6}{|l|}{$\mathrm{CN}$} & \multicolumn{6}{|l|}{ PUT } \\
\hline & Bilateral & $p$ & Right & $p$ & Left & $p$ & Bilateral & $p$ & Right & $p$ & Left & $p$ \\
\hline TMT-A & 0.093 & NS & 0.082 & NS & 0.258 & NS & 0.14 & NS & 0.21 & NS & -0.027 & NS \\
\hline TMT-B & -0.495 & 0.086 & -0.599 & $0.031^{*}$ & -0.154 & NS & -0.545 & 0.067 & -0.497 & NS & -0.604 & $0.029^{*}$ \\
\hline $\mathrm{d} 2 \mathrm{CP}$ & 0.492 & 0.087 & 0.583 & $0.036^{*}$ & 0.294 & NS & 0.75 & $0.005^{* *}$ & 0.701 & 0.011 & 0.707 & $0.007 * *$ \\
\hline Decision bias $\beta$ & 0.214 & NS & 0.192 & NS & 0.154 & NS & -0.056 & NS & 0.007 & NS & -0.016 & NS \\
\hline Discriminability d' & -0.027 & NS & -0.044 & NS & 0.099 & NS & -0.259 & NS & -0.273 & NS & -0.236 & NS \\
\hline
\end{tabular}

CN, Caudate nucleus; PUT, putamen; NS, not significant.

${ }^{*} p<0.05$; ${ }^{* *} p<0.01$.

bilateral caudate nucleus $(Z=-1.842, p=0.072, n=19$, Wilcoxon test). Insofar as this may indicate a carryover effect 2 weeks after $\mathrm{MPH}$ on $\left[{ }^{18} \mathrm{~F}\right] \mathrm{FDOPA}$ kinetics, we analyzed post hoc differences for both groups (Table 4). The results indicate that the increase was $K$ only significant in the reversed-order group.

Relationships between cognitive performance and baseline $K$ Because of the order of treatment effect, correlations between $K$ and neuropsychological measures were conducted only within the conventional order group $(n=14)$. We found that baseline magnitude of $K$ in left putamen correlated negatively with baseline TMT-B: the lower $K$, the better the performance (Fig. $1 b$ ) (TMT-B is measured in seconds, such that briefer duration of the test indicated better working memory). Furthermore, there was a negative correlation between CP ( $\mathrm{d} 2$ test) scores and $K$ in left and right putamen (Table 5; Fig. 1c).

\section{Correlations with change in $k_{\text {loss }}$ and change in neuropsychological measurements}

There was a strong correlation between $\Delta-k_{\text {loss }}$ in bilateral putamen and the improvement in CP under MPH $(r=0.599, p=$ $0.040, n=12$, Spearman; Fig. $1 d)$. Furthermore, $\Delta-k_{\text {loss }}$ in right putamen correlated negatively with the change in decision bias $(\Delta-\beta)$ within the conventional order group $(r=-0.630, p=$ $0.028, n=12$, Spearman).

\section{Discussion}

Using $\left[{ }^{18} \mathrm{~F}\right]$ FDOPA PET in conjunction with the IOM approach for estimation of the dopamine turnover, the present study was designed to quantify direct effects of acute MPH on nigrostriatal dopamine metabolism in healthy females and to link these pharmacodynamic effects to individual cognitive performance changes. We found the expected decrease of $k_{\text {loss }}$ in the $\mathrm{MPH}$ condition. Most likely, $k_{\text {loss }}$ is decreased because of particular action of MPH as a reuptake inhibitor, which decreases the reentry of released dopamine into the intracellular substrate pool for monoamine oxidase. Thus, under $\mathrm{MPH}$, the oxidative deamination of released dopamine to the diffusible metabolite DOPAC by monoamine oxidase is largely disabled (Nielsen et al., 1983; Zetterström et al., 1988). Furthermore, autoreceptor-mediated feedback reduces the formation of diffusible dopamine metabolites. Nonetheless, the magnitude of $K$ was unaffected by acute
MPH treatment, such that the observed changes of volume of distribution $\left(V_{d}\right)$ are mostly driven by $k_{\text {loss. }}$. Baseline parameters for attention performance (CP [d2 test] and TMT-B) correlated with baseline $\left[{ }^{18} \mathrm{~F}\right]$ FDOPA $K$ in putamen; similar results for other cognitive parameters are found in previous studies (Vernaleken et al., 2007, 2008). We also detected significant correlations between $\left[{ }^{18} \mathrm{~F}\right] \mathrm{FDOPA} \Delta-k_{\text {loss }}$ and change of cognitive performance parameters evoked by $\mathrm{MPH}$ : in particular, the individual change of the decision bias $(\Delta \beta)$ and the extent of $k_{\text {loss }}$ reduction correlated positively. Furthermore, $\Delta \mathrm{CP}$ correlated strongly with $\Delta k_{\text {loss }}$, indicating more pronounced attentional improvement in subjects with the greatest pharmacodynamic effect of MPH. Interestingly, our randomized study design revealed a strong PET scan-ordering effect, such that there was an apparent increase in drug-free $\left[{ }^{18} \mathrm{~F}\right]$ FDOPA $K$ (the dopamine synthesis capacity) persisting at 2 weeks after a single, moderate MPH dose.

It is well known that MPH inhibits the plasma membrane catecholamine transporters, causing an increase of intrasynaptic dopamine and noradrenaline concentrations. Volkow et al. $(1998,1999)$ described DAT occupancy of up to $74 \%$ in human subjects treated with MPH. Microdialysis studies have shown doubling of the interstitial dopamine concentration in rat striatum after oral MPH administration (Gerasimov et al., 2000; Berridge et al., 2006). Previous $\mathrm{D}_{2 / 3}$-receptor ligand PET studies have shown availability decreases in healthy subjects ranging from $6 \%$ to $27 \%$ with MPH challenge (Volkow et al., 1994; Udo de Haes et al., 2005; Del Campo et al., 2011). The construct validity of the competition paradigm, however, has some caveats because results depend on which $\mathrm{D}_{2 / 3}$ ligand is used (Gjedde and Wong, 1987; Morris and Yoder, 2007) and an imperfect relation between interstitial dopamine changes and the time course of alterations in receptor availability seen by PET exists (Laruelle et al., 1997; Houston et al., 2004). This discrepancy may be related to receptor internalization and affinity states induced by dopamine agonists. Studies showed internalization effects for amphetamine, dopamine, and dopamine agonists (Bartlett et al., 2005; Skinbjerg et al., 2010). Given these vagaries, we proposed that the $\left[{ }^{18} \mathrm{~F}\right]$ FDOPA IOM should provide a more interpretable assay of the pharmacodynamic effects of a psychostimulant challenge. Indeed, the percentage change of $k_{\text {loss }}$ exceeded that of the $\mathrm{D}_{2 / 3}$-receptor availability seen in many MPH challenge studies. 
The parameter $k_{\text {loss }}$ reflects the composite of partitioning of $\left[{ }^{18} \mathrm{~F}\right] \mathrm{FDOPA}$ between cytosolic and vesicular compartments, release and reuptake, subsequent exposure to monoamine oxidase, and diffusion of deaminated metabolites from brain (Deep et al., 1997). Despite this complexity, we have shown that the $k_{\text {loss }}$ magnitude depicts the steady-state fractional rate constant for dopamine turnover (Deep et al., 1997). As such, our observations of a positive association between decrease of $k_{\text {loss }}$ and MPH-related modulations of cognitive performance link the pharmacodynamic effect of MPH on dopamine metabolism; the more pronounced the decrease in $k_{\text {loss }}$, the less improvement in concentration performance was observed. Analogously, a previous $\left[{ }^{18} \mathrm{~F}\right]$ FDOPA IOM study showed that individual changes in $k_{\text {loss }}$ following haloperidol challenge likewise correlate with cognitive changes (Vernaleken et al., 2008). In the present study, MPH did not evoke cognitive improvement in every case; we suppose that many in our cohort were high achievers with normal IQ, and already in a state of optimal dopamine balance, which could not be improved by MPH challenge. Using the SDT analyses, we detected another important association consistent with procognitive and attention effects of MPH in ADHD patients; participants who manifested the strongest impact of MPH in reducing $k_{\text {loss }}$ also showed the strongest shift to a more conservative decision bias. The decision bias provides a measure of how liberal or conservative the decisions were, regardless of overall performance. These findings might be relevant for several psychiatric disorders that include cognitive disabilities (van Beilen et al., 2008; Jokinen et al., 2013; Kumakura et al., 2013).

The widespread clinical use of psychostimulants in ADHD has raised concerns with respect to long-term treatment effects. Behavioral sensitization to amphetamine is well known in rodent studies (Robinson et al., 1982), and previous MPH treatment evokes persistent changes in interstitial dopamine (Calipari et al., 2013, 2014) and NMDA receptors in rat brain (Urban et al., 2013). A human PET study revealed potentiation of reductions in amphetamine-evoked $\mathrm{D}_{2 / 3}$-receptor availability some months after the previous dose of amphetamine, indicating persistent sensitization (Boileau et al., 2006). Based on these results, our study design included a subgroup with a reversed order of the drug-free and pharmacological challenge $\left[{ }^{18} \mathrm{~F}\right] \mathrm{FDOPA}$ PET scans. We did see an order effect on the magnitude of $K$; MPH treatment 2 weeks before the scan significantly $(\sim 18 \%)$ increased striatal dopamine synthesis capacity. This presynaptic change might have arisen through feedback regulation of dopamine autoreceptors, which could likewise be a factor in the amphetamine sensitization reported by Boileau et al. (2006). Verification of the presynaptic potentiation would require prospective $\left[{ }^{18} \mathrm{~F}\right] \mathrm{FDOPA}$ studies with repeated psychostimulant challenge. Ernst et al. (1999) found that ADHD patients had increased $\left[{ }^{18} \mathrm{~F}\right] \mathrm{FDOPA}$ uptake in midbrain compared with healthy subjects, despite being drug free for several weeks. Present findings suggest that this, too, may have reflected a carryover effect rather than an ADHD trait per se. Our main endpoint in the present study, $k_{\text {loss }}$, obviously is a more volatile parameter, being related to present state of dopamine turnover. Consistent with this conception, we saw no evidence for a carryover in the magnitude of $k_{\text {loss }}$. If further studies replicate our finding of persistently increased dopamine synthesis capacity following MPH, it will become an issue whether this effect contributes to the beneficial clinical effects in ADHD, which are usually attributed to the acute increase of dopamine levels.

Some limitations of the present study should be noted. In general, the complex nature of $\left[{ }^{18} \mathrm{~F}\right]$ FDOPA metabolism in brain (Cumming et al., 1987) hampers the interpretation of our findings.
The IOM, which accommodates the reversibility of $\left[{ }^{18} \mathrm{~F}\right] \mathrm{FDOPA}$ trapping, is necessarily a simplification of the biological complexity of dopamine metabolism. As noted above, our main endpoint $k_{\text {loss }}$ is explicable as an index of dopamine turnover, traced by the elimination of the $\left[{ }^{18} \mathrm{~F}\right] \mathrm{FDOPA}$ pool formed in striatum, such that a reduction of $k_{\text {loss }}$ reflects a decline in turnover. Our previous results confirm the (patho)physiological relevance of disturbed $k_{\text {loss }}$ in psychiatric and neurological disorders (Kumakura et al., 2007). In contrast, the $\left[{ }^{18} \mathrm{~F}\right] \mathrm{FDOPA}$ parameter $K$ represents the capacity to use (exogenous) $\left[{ }^{18} \mathrm{~F}\right] \mathrm{FDOPA}$ in brain, which is hardly subject to regulation upon acute MPH challenge. We previously reported changes in $\left[{ }^{18} \mathrm{~F}\right] \mathrm{FDOPA} K$ upon treatment for $3 \mathrm{~d}$ with a $\mathrm{D}_{2 / 3}$-anatgonist (Vernaleken et al., 2008), whereas short-term antipsychotic treatment had no effect on corresponding m-tyrosine PET findings (Mamo et al., 2004; Vernaleken et al., 2006). Our design deliberately entailed a test of order effect on $\left[{ }^{18} \mathrm{~F}\right]$ FDOPA kinetics, which revealed $k_{\text {loss }}$ to be robust to this factor, whereas $K$ was increased by previous MPH exposure. Our subjects did not otherwise report any previous use of psychostimulants, so we feel confident in our observation of a main effect of MPH challenge on $k_{\text {loss }}$. In clinical $\left[{ }^{18} \mathrm{~F}\right]$ FDOPA studies of ADHD patients, drug treatment history is very likely to be relevant, given that $K$ was strongly affected by previous one-time MPH use. Nevertheless, the unequal group sizes call for caution in the interpretation of this finding. The group with the reversed treatment order $(n=6)$ was smaller than the group with standard scanning order $(n=14)$. This was, by design, to provide sufficient power for testing the main hypotheses concerning correlations between PET and cognitive changes. Also notably, the test-retest variability is $10 \%$ for conventional reference tissue $\left[{ }^{18} \mathrm{~F}\right]$ FDOPA PET (Egerton et al., 2010); the corresponding covariance remains to be established for the IOM method. Given that a possibly higher variance in the outcome parameters of the IOM might exist, which would impair the test-retest reliability, from a statistical point of view, this would not relativize the fact that, based on the present observations, the probability to reject a possible true null hypothesis is $<5 \%$ (risk of false positive as depicted by $\alpha \leq 0.05$ ). Lower test-retest reliability, however, depends on higher necessary effects to contrast against the higher level of noise in the data.

\section{Notes}

Supplemental material for this article is available at http://www.ukaachen.de/ fileadmin/files/klinik-psychiatrie/Download_Personen/The_reversible_ Inlet-Outlet_Model.pdf. Detailed description of the reversible Inlet/Outlet Model. Giving a more complete overview and a better understanding of the kinetic model which is used in this manuscript. This material has not been peer reviewed.

\section{References}

Bartlett SE, Enquist J, Hopf FW, Lee JH, Gladher F, Kharazia V, Waldhoer M, Mailliard WS, Armstrong R, Bonci A, Whistler JL (2005) Dopamine responsiveness is regulated by targeted sorting of D2 receptors. Proc Natl Acad Sci U S A 102:11521-11526. CrossRef Medline

Bäumler G (1985) Farbe-Wort-Interferenztest (FWIT) nach J. R. Stroop (Handanweisung). Göttingen, Germany: Verlag fur Psychologie Hogrefe. Berridge CW, Devilbiss DM, Andrzejewski ME, Arnsten AF, Kelley AE, Schmeichel B, Hamilton C, Spencer RC (2006) Methylphenidate preferentially increases catecholamine neurotransmission within the prefrontal cortex at low doses that enhance cognitive function. Biol Psychiatry 60:1111-1120. CrossRef Medline

Boileau I, Dagher A, Leyton M, Gunn RN, Baker GB, Diksic M, Benkelfat C (2006) Modeling sensitization to stimulants in humans: an $\left[{ }^{11} \mathrm{C}\right]$ raclopride/positron emission tomography study in healthy men. Arch Gen Psychiatry 63:1386-1395. CrossRef Medline 
Brickenkamp R (2002) Test d2 Aufmerksamkeits und Konzentrationstest, Ed 9. Göttingen, Germany: Hogrefe.

Calipari ES, Ferris MJ, Salahpour A, Caron MG, Jones SR (2013) Methylphenidate amplifies the potency and reinforcing effects of amphetamines by increasing dopamine transporter expression. Nat Commun 4:2720. CrossRef Medline

Calipari ES, Ferris MJ, Melchior JR, Bermejo K, Salahpour A, Roberts DC, Jones SR (2014) Methylphenidate and cocaine self-administration produce distinct dopamine terminal alterations. Addict Biol 19:145-155. CrossRef Medline

Cumming P, Gjedde A (1998) Compartmental analysis of dopa decarboxylation in living brain from dynamic positron emission tomograms. Synapse 29:37-61. CrossRef Medline

Cumming P, Boyes BE, Martin WR, Adam M, Grierson J, Ruth T, McGeer EG (1987) The metabolism of [18F]6-fluoro-L-3,4-dihydroxyphenylalanine in the hooded rat. J Neurochem 48:601-608. CrossRef Medline

Cumming P, Léger GC, Kuwabara H, Gjedde A (1993) Pharmacokinetics of plasma 6-[18F]fluoro-L-3,4-dihydroxyphenylalanine ([18F]Fdopa) in humans. J Cereb Blood Flow Metab 13:668-675. CrossRef Medline

Cumming P, Munk OL, Doudet D (2001) Loss of metabolites from monkey striatum during PET with FDOPA. Synapse 41:212-218. CrossRef Medline

Deep P, Gjedde A, Cumming P (1997) On the accuracy of an $\left[{ }^{18} \mathrm{~F}\right] \mathrm{FDOPA}$ compartmental model: evidence for vesicular storage of $\left[{ }^{18} \mathrm{~F}\right]$ fluorodopamine in vivo. J Neurosci Methods 76:157-165. CrossRef Medline

Del Campo N, Chamberlain SR, Sahakian BJ, Robbins TW (2011) The roles of dopamine and noradrenaline in the pathophysiology and treatment of attention-deficit/hyperactivity disorder. Biol Psychiatry 69:e145-e157. CrossRef Medline

Egerton A, Demjaha A, McGuire P, Mehta MA, Howes OD (2010) The test-retest reliability of 18F-DOPA PET in assessing striatal and extrastriatal presynaptic dopaminergic function. Neuroimage 50:524-531. CrossRef Medline

Ernst M, Zametkin AJ, Matochik JA, Jons PH, Cohen RM (1998) DOPA decarboxylase activity in attention deficit hyperactivity disorder adults: a [fluorine- ${ }^{18}$ ]fluorodopa positron emission tomographic study J Neurosci 18:5901-5907. Medline

Ernst M, Zametkin AJ, Matochik JA, Pascualvaca D, Jons PH, Cohen RM (1999) High midbrain $\left[{ }^{18} \mathrm{~F}\right]$ DOPA accumulation in children with attention deficit hyperactivity disorder. Am J Psychiatry 156:1209-1215. Medline

Gerasimov MR, Franceschi M, Volkow ND, Gifford A, Gatley SJ, Marsteller D, Molina PE, Dewey SL (2000) Comparison between intraperitoneal and oral methylphenidate administration: a microdialysis and locomotor activity study. J Pharmacol Exp Ther 295:51-57. Medline

Gillings NM, Bender D, Falborg L, Marthi K, Munk OL, Cumming P (2001) Kinetics of the metabolism of four PET radioligands in living minipigs. Nucl Med Biol 28:97-104. CrossRef Medline

Gjedde A, Wong DF (1987) Positron tomographic quantitation of neuroreceptors in human brain in vivo: with special reference to the $\mathrm{D} 2$ dopamine receptors in caudate nucleus. Neurosurg Rev 10:9-18. CrossRef Medline

Gjedde A, Reith J, Dyve S, Léger G, Guttman M, Diksic M, Evans A, Kuwabara H (1991) Dopa decarboxylase activity of the living human brain. Proc Natl Acad Sci U S A 88:2721-2725. CrossRef Medline

Gründer G, Vernaleken I, Müller MJ, Davids E, Heydari N, Buchholz HG, Bartenstein P, Munk OL, Stoeter P, Wong DF, Gjedde A, Cumming P (2003) Subchronic haloperidol downregulates dopamine synthesis capacity in the brain of schizophrenic patients in vivo. Neuropsychopharmacology 28:787-794. CrossRef Medline

Houston GC, Hume SP, Hirani E, Goggi JL, Grasby PM (2004) Temporal characterisation of amphetamine-induced dopamine release assessed with $\left[{ }^{11} \mathrm{C}\right]$ raclopride in anaesthetised rodents. Synapse 51:206-212. CrossRef Medline

Huang SC, Barrio JR, Yu DC, Chen B, Grafton S, Melega WP, Hoffman JM, Satyamurthy N, Mazziotta JC, Phelps ME (1991) Modelling approach for separating blood time-activity curves in positron emission tomographic studies. Phys Med Biol 36:749-761. CrossRef Medline

Jokinen P, Karrasch M, Brück A, Johansson J, Bergman J, Rinne JO (2013) Cognitive slowing in Parkinson's disease is related to frontostriatal dopaminergic dysfunction. J Neurol Sci 329:23-28. CrossRef Medline

Kathmann N, Wagner M, Satzger W, Engel RR (1996) Vigilanzmessung auf verhaltensebene: Der continuous performance test- münchen (cpt-m).
In: Befunderhebungin der psychiatrie: Lebensqualität, negativsymptomatik und andere aktuelle entwicklungen (Möller HJ, Engel RR, Hoff P, eds), pp 331-338. Vienna: Springer.

Kumakura Y, Cumming P, Vernaleken I, Buchholz HG, Siessmeier T, Heinz A, Kienast T, Bartenstein P, Gründer G (2007) Elevated $\left[{ }^{18} \mathrm{~F}\right]$ fluorodopamine turnover in brain of patients with schizophrenia: an $\left[{ }^{18} \mathrm{~F}\right]$ fluorodopa/positron emission tomography study. J Neurosci 27:8080-8087. CrossRef Medline

Kumakura Y, Gjedde A, Caprioli D, Kienast T, Beck A, Plotkin M, Schlagenhauf F, Vernaleken I, Gründer G, Bartenstein P, Heinz A, Cumming P (2013) Increased turnover of dopamine in caudate nucleus of detoxified alcoholic patients. PLoS One 8:e73903. CrossRef Medline

Laruelle M, Iyer RN, al-Tikriti MS, Zea-Ponce Y, Malison R, Zoghbi SS, Baldwin RM, Kung HF, Charney DS, Hoffer PB, Innis RB, Bradberry CW (1997) Microdialysis and SPECT measurements of amphetamineinduced dopamine release in nonhuman primates. Synapse 25:1-14. CrossRef Medline

Lee MD (2008) BayesSDT: software for Bayesian inference with signal detection theory. Behav Res Methods 40:450-456. CrossRef Medline

Ludolph AG, Kassubek J, Schmeck K, Glaser C, Wunderlich A, Buck AK, Reske SN, Fegert JM, Mottaghy FM (2008) Dopaminergic dysfunction in attention deficit hyperactivity disorder (ADHD), differences between pharmacologically treated and never treated young adults: a 3,4dihdroxy-6-[18F]fluorophenyl-1-alanine PET study. Neuroimage 41: 718-727. CrossRef Medline

Mamo D, Remington G, Nobrega J, Hussey D, Chirakal R, Wilson AA, Baker G, Houle S, Kapur S (2004) Effect of acute antipsychotic administration on dopamine synthesis in rodents and human subjects using $6-\left[{ }^{18} \mathrm{~F}\right]-\mathrm{L}-$ m-tyrosine. Synapse 52:153-162. CrossRef Medline

Markowitz JS, Straughn AB, Patrick KS, DeVane CL, Pestreich L, Lee J, Wang Y, Muniz R (2003) Pharmacokinetics of methylphenidate after oral administration of two modified-release formulations in healthy adults. Clin Pharmacokinet 42:393-401. CrossRef Medline

Mazziotta J, Toga A, Evans A, Fox P, Lancaster J, Zilles K, Woods R, Paus T, Simpson G, Pike B, Holmes C, Collins L, Thompson P, MacDonald D, Iacoboni M, Schormann T, Amunts K, Palomero-Gallagher N, Geyer S, Parsons L, et al. (2001) A probabilistic atlas and reference system for the human brain: International Consortium for Brain Mapping (ICBM). Philos Trans R Soc Lond B Biol Sci 356:1293-1322. CrossRef Medline

Morris ED, Yoder KK (2007) Positron emission tomography displacement sensitivity: predicting binding potential change for positron emission tomography tracers based on their kinetic characteristics. J Cereb Blood Flow Metab 27:606-617. CrossRef Medline

Nielsen JA, Chapin DS, Moore KE (1983) Differential effects of d-amphetamine, beta-phenylethylamine, cocaine and methylphenidate on the rate of dopamine synthesis in terminals of nigrostriatal and mesolimbic neurons and on the efflux of dopamine metabolites into cerebroventricular perfusates of rats. Life Sci 33:1899-1907. CrossRef Medline

Peterson WW, Birdsall TG, Fox WC (1954) The theory of signal detectability. Trans IRE Group on Information Theory PGIT 4:171-212. CrossRef

Reitan RM (1955) The relation of the trail making test to organic brain damage. J Consult Psychol 19:393-394. CrossRef Medline

Robinson TE, Becker JB, Presty SK (1982) Long-term facilitation of amphetamine-induced rotational behavior and striatal dopamine release produced by a single exposure to amphetamine: sex differences. Brain Res 253:231-241. CrossRef Medline

Rosa-Neto P, Lou HC, Cumming P, Pryds O, Karrebaek H, Lunding J, Gjedde A (2005) Methylphenidate-evoked changes in striatal dopamine correlate with inattention and impulsivity in adolescents with attention deficit hyperactivity disorder. Neuroimage 25:868-876. CrossRef Medline

Sankoh AJ, Huque MF, Dubey SD (1997) Some comments on frequently used multiple endpoint adjustment methods in clinical trials. Stat Med 16:2529-2542. CrossRef Medline

Schabram I, Eggermann T, Siegel SJ, Gründer G, Zerres K, Vernaleken I (2013) Neuropsychological correlates of transcription factor AP-2Beta, and its interaction with COMT and MAOA in healthy females. Neuropsychobiology 68:79-90. CrossRef Medline

Skinbjerg M, Liow JS, Seneca N, Hong J, Lu S, Thorsell A, Heilig M, Pike VW, Halldin C, Sibley DR, Innis RB (2010) D2 dopamine receptor internalization prolongs the decrease of radioligand binding after amphetamine: a PET study in a receptor internalization-deficient mouse model. Neuroimage 50:1402-1407. CrossRef Medline 
Sossi V, Doudet DJ, Holden JE (2001) A reversible tracer analysis approach to the study of effective dopamine turnover. J Cereb Blood Flow Metab 21:469-476. CrossRef Medline

Udo de Haes JI, Kortekaas R, Van Waarde A, Maguire RP, Pruim J, den Boer JA (2005) Assessment of methylphenidate-induced changes in binding of continuously infused $[(11) \mathrm{C}]$-raclopride in healthy human subjects: correlation with subjective effects. Psychopharmacology (Berl) 183:322330. CrossRef Medline

Urban KR, Li YC, Gao WJ (2013) Treatment with a clinically-relevant dose of methylphenidate alters NMDA receptor composition and synaptic plasticity in the juvenile rat prefrontal cortex. Neurobiol Learn Mem 101:65-74. CrossRef Medline

van Beilen M, Portman AT, Kiers HA, Maguire RP, Kaasinen V, Koning M, Pruim J, Leenders KL (2008) Striatal FDOPA uptake and cognition in advanced non-demented Parkinson's disease: a clinical and FDOPA PET study. Parkinsonism Relat Disord 14:224-228. CrossRef Medline

Vernaleken I, Kumakura Y, Cumming P, Buchholz HG, Siessmeier T, Stoeter P, Müller MJ, Bartenstein P, Gründer G (2006) Modulation of $\left[{ }^{18} \mathrm{~F}\right]$ fluorodopa (FDOPA) kinetics in the brain of healthy volunteers after acute haloperidol challenge. Neuroimage 30:1332-1339. CrossRef Medline

Vernaleken I, Buchholz HG, Kumakura Y, Siessmeier T, Stoeter P, Bartenstein P, Cumming P, Gründer G (2007) 'Prefrontal' cognitive performance of HS positively correlates with cerebral FDOPA influx: an exploratory $\left[{ }^{18} \mathrm{~F}\right]$-fluoro-L-DOPA PET investigation. Hum Brain Mapp 28:931-939. CrossRef Medline

Vernaleken I, Kumakura Y, Buchholz HG, Siessmeier T, Hilgers RD, Bartenstein P, Cumming P, Gründer G (2008) Baseline $\left[{ }^{18} \mathrm{~F}\right]$-FDOPA kinetics are predictive of haloperidol-induced changes in dopamine turnover and cognitive performance: a positron emission tomography study in healthy subjects. Neuroimage 40:1222-1231. CrossRef Medline

Vernaleken I, Rademacher L, Henkel K, Dietrich C, Prinz S, Winz O, Schmaljohann J, Mohammadkhani Shali S, Mottaghy F, Gründer G (2013) A longitudal $\left[{ }^{18} \mathrm{~F}\right]$ FDOPA PET study on nicotine addicted patients. J Nucl Med 54. (Supplement 2):31.

Volkow ND, Wang GJ, Fowler JS, Logan J, Schlyer D, Hitzemann R, Lieberman J, Angrist B, Pappas N, MacGregor R (1994) Imaging endogenous dopamine competition with $\left[{ }^{11} \mathrm{C}\right]$ raclopride in the human brain. Synapse 16:255-262. CrossRef Medline

Volkow ND, Wang GJ, Fowler JS, Gatley SJ, Logan J, Ding YS, Hitzemann R, Pappas N (1998) Dopamine transporter occupancies in the human brain induced by therapeutic doses of oral methylphenidate. Am J Psychiatry 155:1325-1331. Medline

Volkow ND, Wang GJ, Fowler JS, Gatley SJ, Logan J, Ding YS, Dewey SL, Hitzemann R, Gifford AN, Pappas NR (1999) Blockade of striatal dopamine transporters by intravenous methylphenidate is not sufficient to induce self-reports of "high." J Pharmacol Exp Ther 288:14-20.

Volkow ND, Wang GJ, Newcorn J, Fowler JS, Telang F, Solanto MV, Logan J, Wong C, Ma Y, Swanson JM, Schulz K, Pradhan K (2007) Brain dopamine transporter levels in treatment and drug naive adults with ADHD. Neuroimage 34:1182-1190. CrossRef Medline

Zetterström T, Sharp T, Collin AK, Ungerstedt U (1988) In vivo measurement of extracellular dopamine and DOPAC in rat striatum after various dopamine-releasing drugs; implications for the origin of extracellular DOPAC. Eur J Pharmacol 148:327-334. CrossRef Medline 